\title{
Molecular characterisation of cell line models for triple-negative breast cancers
}

\author{
Anita Grigoriadis ${ }^{1 *}$, Alan Mackay², Elodie Noel', Pei Jun Wu' ${ }^{1}$, Rachel Natrajan², Jessica Frankum², \\ Jorge S Reis-Filho ${ }^{2,3}$ and Andrew Tutt $^{1}$
}

\begin{abstract}
Background: Triple-negative breast cancers (BC) represent a heterogeneous subtype of BCs, generally associated with an aggressive clinical course and where targeted therapies are currently limited. Target validation studies for all BC subtypes have largely employed established BC cell lines, which have proven to be effective tools for drug discovery.

Results: Given the lines of evidence suggesting that BC cell lines are effective tools for drug discovery, we assessed the similarities between triple-negative BCs and cell lines, to identify in vitro representatives, modelling the diversity within this BC subtype. 25 BC cell lines, enriched for those lacking ER, PR and HER2 expression, were subjected to transcriptomic, genomic and epigenomic profiling analyses and comparisons were made to existing knowledge of corresponding perturbations in triple-negative BCs. Transcriptional analysis segregated ER-negative BC cell lines into three groups, displaying distinctive abundances for genes involved in epithelial-mesenchymal transition, apocrine and high-grade carcinomas. DNA copy number aberrations of triple-negative BCs were well represented in cell lines and genes with coordinately altered gene expression showed similar patterns in tumours and cell lines. Methylation events in triple-negative BCs were mostly retained in epigenomes of cell lines. Combined methylation and gene expression analyses revealed a subset of genes characteristic of the Claudin-low BC subtype, exhibiting epigenetic-regulated gene expression in BC cell lines and tumours, suggesting that methylation patterns are likely to underpin subtype-specificity.

Conclusion: Here, we provide a comprehensive analysis of triple-negative BC features on several molecular levels in $\mathrm{BC}$ cell lines, thereby creating an in-depth resource to access the suitability of individual lines as experimental models for studying BC tumour biology, biomarkers and possible therapeutic targets in the context of preclinical target validation.
\end{abstract}

Keywords: Microarray, Gene expression profiling, Comparative genomic hybridisation, Methylation arrays, Triple negative, Breast cancer

\section{Background}

Oestrogen-receptor (ER) negative breast cancer (BC) accounts for approximately $20 \%$ of all newly diagnosed breast malignancies [1-3]. Clinically, however, this group of BCs contains different subtypes and can be subdivided into either HER2-positive or triple-negative BCs, defined by very low or absent immunohistochemical expression of ER and progesterone receptor (PR), and

\footnotetext{
*Correspondence: Anita.grigoriadis@kcl.ac.uk

'Breakthrough Breast Cancer Research Unit, Guy's Hospital, King's Health Partners AHSC, King's College London School of Medicine, London SE1 9RT, UK

Full list of author information is available at the end of the article
}

low expression and lack of amplification of HER2 [4]. Triple-negative BCs account for 10-15\% of all breast tumours and are mostly of high grade, have a high incidence of TP53 mutations, and show proliferative characteristics with a higher propensity to spread to visceral organs [4]. Sharing many of these phenotypic features with triple-negative $\mathrm{BCs}$ are breast tumours of the 'intrinsic' basal-like subtype. These tumours generally lack ER and HER2 expression and are molecularly characterised by the expression of genes associated with both basal epithelium and myoepithelium of the normal mammary gland (e.g. KRT5/6, KRT14, VIM, CDH3, CRYAB, CAV1 and CAV2, as well as EGFR) [2,5]. Approximately,

\section{Ciomed Central}


$80 \%$ of triple-negative BCs show features of basal-like BCs $[4,6,7]$. While most triple-negative BCs show aggressive clinical behaviour and have very limited targeted therapies, they also encompass subgroups of cancers sensitive to chemotherapy and having a good prognosis [4]. Hence, continuous efforts to characterise this $\mathrm{BC}$ population have already identified several subgroups. One of the proposed groups comprise "Claudin-low" tumours, which are characterised by gene expression profiles similar to those found in the so-called breast 'cancer stem cell' populations [8], while other subgroups were classified as having higher expression of the interferon-related or apocrine genes [9-12]. BC cell lines are essential tools in BC research and have been widely used to elucidate $\mathrm{BC}$ biology and new therapies $[13,14]$. Since cell lines are easily propagated and genetically manipulated, extensive information about their transcriptome, genome and to a lesser extent epigenome has been produced [11,15-19]. Several studies have compared and integrated gene expression profiles and genomic alterations between primary breast tumours and $\mathrm{BC}$ cell lines, demonstrating that the heterogeneity found in primary $\mathrm{BCs}$ is to a certain extent recapitulated in the panel of commonly used BC cell lines $[15,16,18]$. Given the increasing knowledge of the diversity and complexity among $\mathrm{BC}$ subtypes it has also become evident that no individual cell line will recapitulate all aspects of the disease. Here we interrogated genome-wide transcriptional profiles with genomic and epigenetic profiling in a collection of $25 \mathrm{BC}$ cell lines enriched for those of triple-negative phenotype. We have focused on gene signatures, underlying DNA copy number aberrations (CNAs) and epigenetic events specifically associated with triple-negative BCs. By cataloguing these perturbations on a gene-centric basis we have extended the characterisation of these BC cell lines and offer valuable insights on their suitability in modelling certain features of this heterogeneous disease.

\section{Results}

BC cell lines segregate into three groups based on their transcriptional profiles

To investigate the molecular heterogeneity of triple-negative $\mathrm{BC}$ cell lines and their representativeness of triple-negative breast cancers, we used Illumina HumanWG-6v2.0 to survey the phenotypic and genotypic characteristics of seven ER-negative mesenchymal BC cell lines (Hs578T, BT549, MDAMD157, MDAMD231, MDAMD436 and SUM159) and compared them with 13 ER-negative epithelial-like BC cell lines (BT20, HCC38, HCC70, HCC1143, HCC1937, MDAMD468, SUM149, SKBR3, SUM190, SUM225). Five ER-positive BC cell lines (T47D, BT474, ZR7530, BT483 and HCC1428) were also included in our dataset, to evaluate ER-responsive transcriptional signatures in ER-negative $\mathrm{BC}$ cell lines.
In addition, two ER-negative/ HER2-positive epithelial BC cell lines were included (i.e. HCC1954 and HCC1569), and were employed as comparators with other triplenegative $\mathrm{BC}$ cell lines. Molecular pathological features of all BC cell lines are provided in Additional file 1 Table S1. Unsupervised hierarchical clustering of 5,693 highly variable Ensembl genes separated ER-negative BC cell lines into three groups (Figure 1). One group, designated "Cluster 1" (blue lines, Figure 1) included three ER-negative/HER2-positive BC cell lines, namely SKBR3, SUM190 and SUM225, which clustered with ER-positive/ HER2-negative (T47D, HCC1428 and BT483) and ER-positive/HER2-positive (BT474, ZRF7530) cell lines. "Cluster 2" was uniformly composed of ER-negative/ HER2-negative BC cell lines (orange lines, Figure 1) and was in complete concordance with the Basal "B" BC cell line subtype described in previous $\mathrm{BC}$ cell line studies [16-18]. "Cluster 3" consisted of cell lines (red lines, Figure 1) either having a triple-negative phenotype or showing amplification and higher abundance of HER2 (HCC1954, HCC1569) and EGFR gene amplification (BT20, MDAMB468). Investigating the expression levels of known triple-negative $\mathrm{BC}$-related genes demonstrated subtle differences within these three groups. While "Cluster 3" cell lines expressed genes commonly found in the intrinsic gene list preferentially expressed in basal-like primary $\mathrm{BC}$ (e.g. LCN, RARRES1, CLDN1, KRT17; Figure 1B) [20], "Cluster 2" was characterised by a higher abundance of $C A V 1$, a marker for the basallike phenotype of sporadic and hereditary breast cancers [21], and the lymphangiogenic factor $V E G F C$, a potential therapeutic target for triple-negative BCs [22] (Figure 1C). Other genes previously associated with triple-negative BCs such as $c-M E T, C D 44$ and CAV2 [23,24] exhibited higher expression in both groups in comparison to "Cluster 1" cell lines (Figure 1D).

\section{Representation of ER-negative breast tumour-related gene signatures in $\mathrm{BC}$ cell lines}

Given that the combined expression pattern of certain genes can uniquely characterise different $\mathrm{BC}$ subtypes or can be used as surrogate markers for pathway activation, we selected a compendium of gene signatures representing various features of triple-negative BCs. Firstly, we investigated the representation of eleven gene signatures based on a "relative similarity score" and ranked the BC cell lines accordingly (Additional file 2 Table S2). Overall "Cluster 3" cell lines (red names, Figure 2) showed a good representation of gene signatures identified for "Apocrine", G3. TN.Tumour" and high-grade breast carcinomas, while "Cluster 2" cell lines exhibited high similarities with the "Stroma", "Mammosphere" and "CD24.CD44" expression patterns (orange names, Figure 2). The resemblance to the remaining four gene signatures showed a 

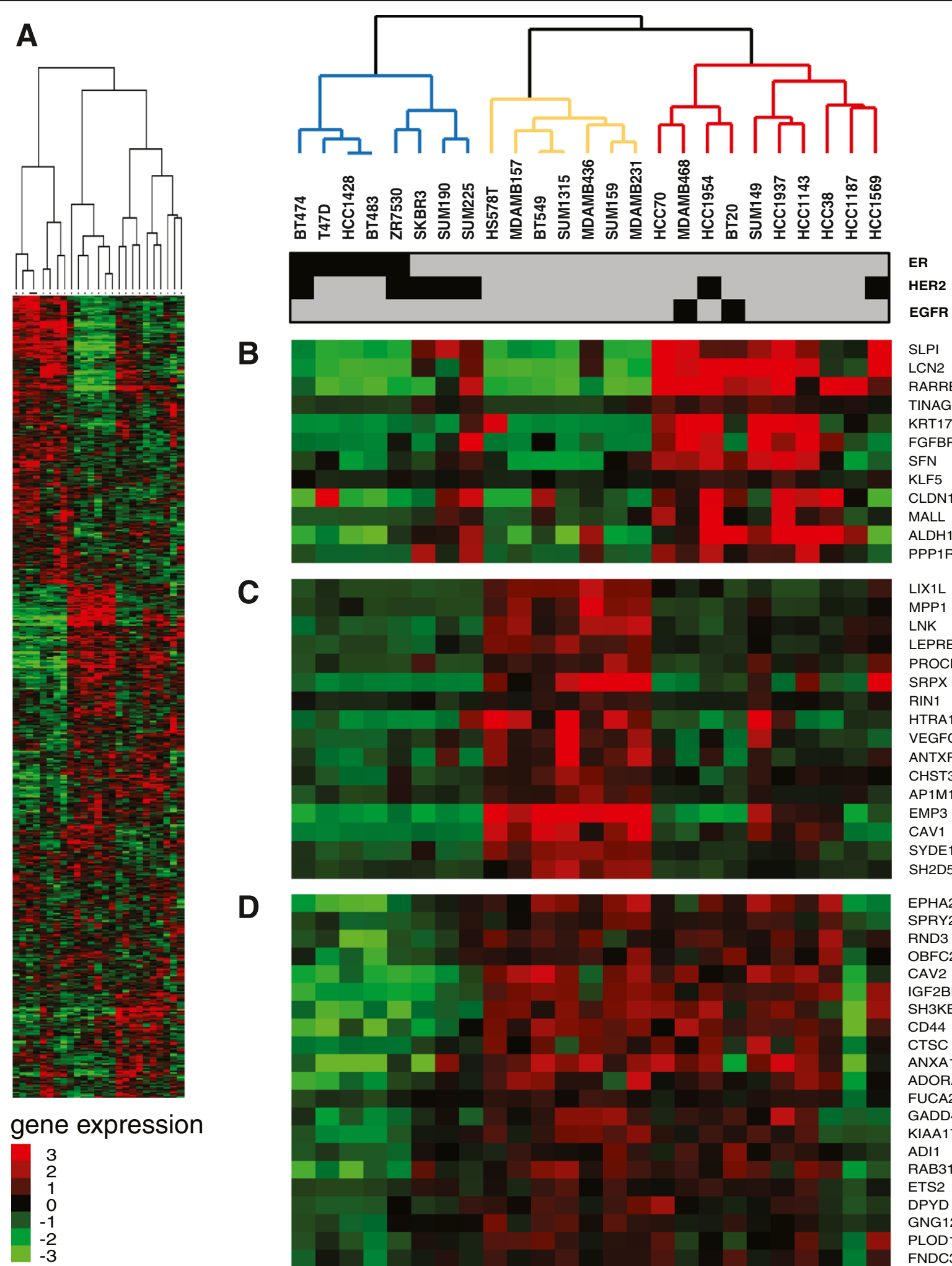

B

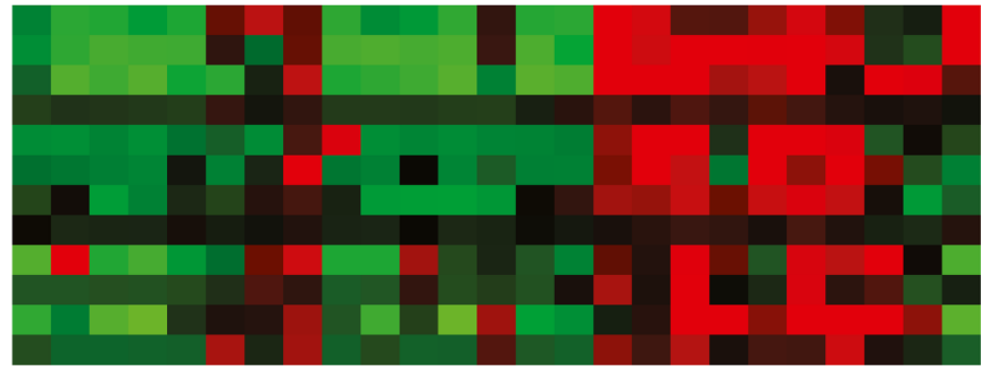

SLPI

LCN2

RARRES1

TINAGL1

KRT17

FGFBP1

SFN

KLF5

CLDN1

MALL

ALDH1A3

C

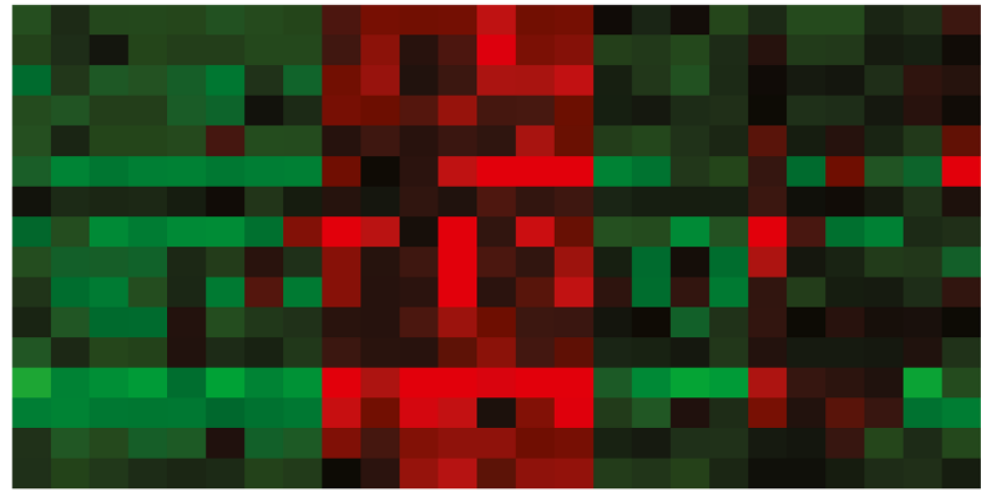

IX1L

MPP1

LNK

LEPRE1

PROCR

SRPX

RIN1

HTRA1

VEGFC

ANTXR2

CHST3

AP1M1

EMP3

CAV1

SYDE1

SH2D5

D

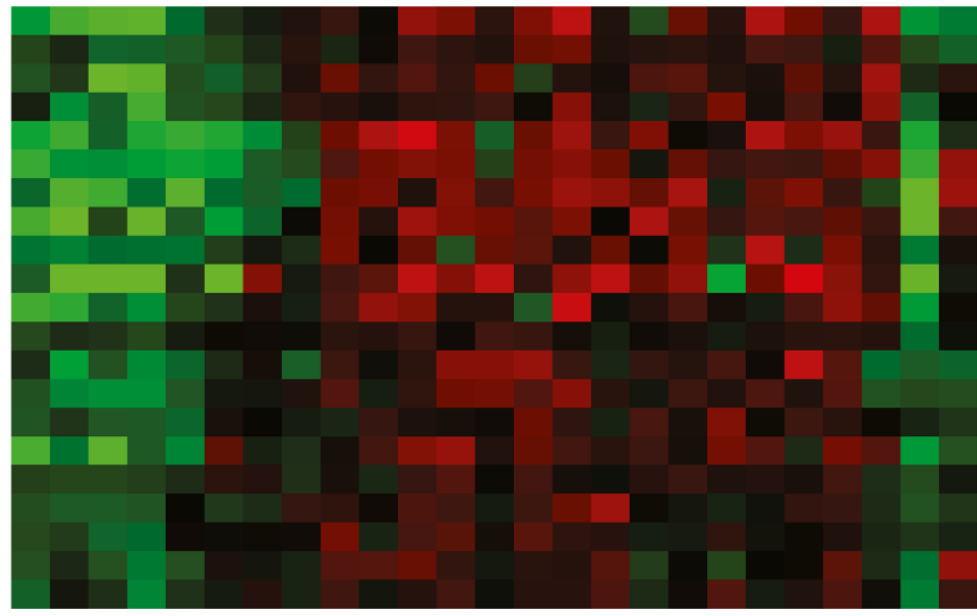

EPHA2

SPRY2

RND3

OBFC2A

CAV2

IGF2BP2

SH3KBP1

CD44

CTSC

ANXA1

ADORA2B

FUCA2

GADD45A

KIAA1754

ADI1

RAB31

ETS2

DPYD

GNG12

PLOD1

FNDC3B

Figure 1 Subtype-specific gene expression and molecular characteristics of breast cancer cell lines, using the Illumina HumanWG-6v2.0 microarray platform. (A) "Two-way" hierarchical clustering of $25 \mathrm{BC}$ cell lines and 5,693 variably expressed genes segregate into three groups, "Cluster 1, 2 and 3" indicated as blue, orange and red dendrogram branches. (B) Selected cluster commonalities in gene expression for "Cluster 2"; (C) "Cluster 3"; and (D) both cell lines clusters are shown. Bar below dendrogram indicates phenotypic features of cell lines for ER, HER2 and EGFR. 


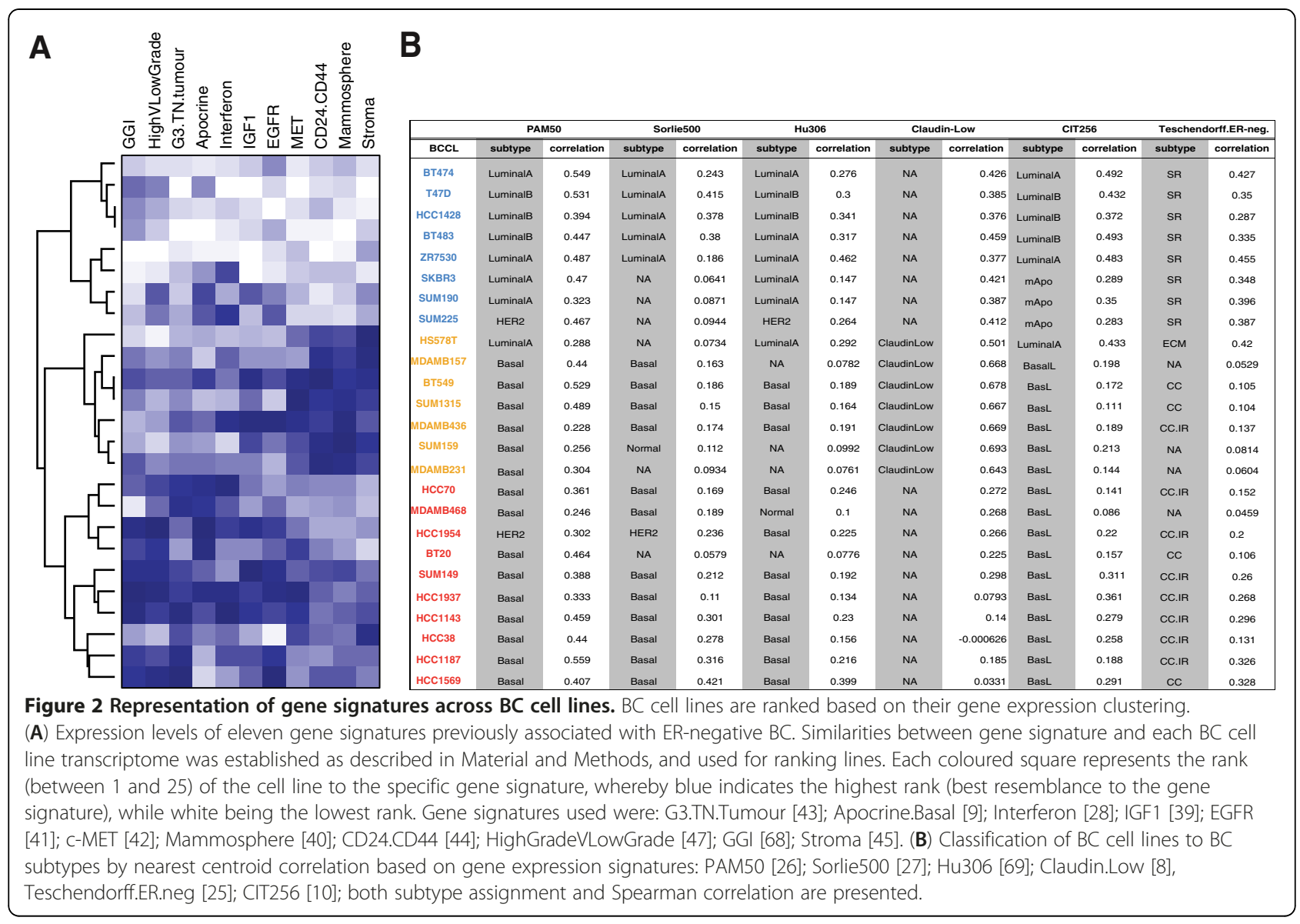

less striking concordance with the gene expression defined clusters, and identified SUM1315, HCC1569, SUM149 and HCC1143 cell lines as the best representatives for the "MET", "EGFR", "IGF1" and "Interferon" gene signatures, respectively. Secondly, we examined the 5 different ER-negative $\mathrm{BC}$ subgroups associated with a prognostic outcome [25] in the $\mathrm{BC}$ cell line transcriptomes based on centroid correlation classification. As shown in Figure 2B, "Cluster 3" cell lines had activation of the "cell cycle and cell proliferation pathway/immune response genes" and the "cell cycle and cell proliferation pathway" groups (Figure 2B), both of which showed association to basal-like BCs in their study [25]. In contrast, "Cluster 1" cell lines displayed highest correlation to ER-negative tumours of the steroid response group, supporting the outcome of our hierarchical clustering in which these cell lines group with the ER-positive cell lines (Figure 1). Lastly, to explore the representation of the molecular basal-like $\mathrm{BC}$ subtype within this $\mathrm{BC}$ cell line set, we performed nearest centroid classification using the class centroids from Parker et al. [26], Sorlie et al. [27], $\mathrm{Hu}$ et al. [28], Prat et al. [8] and Guedj et al., [10] (referred to as PAM50, Sorlie500, Hu306, Claudin.Low and CIT256 respectively, in Figure 2B). As expected given the manner in which the "Claudin.Low" gene signature was originally established [8], "Cluster 2" cell lines (Hs578T, MDAMB157, MDAMB231, MDAMB436, BT549, SUM159 and SUM1315) are representatives of the described "Claudin.Low" subtype. The recently published CIT classification [10] assigned all "Cluster 2" and "Cluster 3 " cell lines to the basalL group (Figure 2B) with the exception of Hs578T which was assigned to the "LuminalA" subtype. Interestingly, in "Cluster 1", ER-negative/HER2positive cell lines SKBR3, SUM190 and SUM225 were labelled as mApo ('molecular Apocrine') groups, in agreement with ER-negative/HER2-positive breast carcinomas in this molecular subtype [9]. PAM50 classification assigned all "Cluster 2 and 3" BC cell lines except Hs578T and HCC1954 to the basal-like BC subtype. Assignments of cell lines into the basal-like subtype with class centroids obtained from Sorlie500 and Hu306 were in good agreement with those obtained with PAM50, however only 2 out 10 cell lines were consistently classified as of luminal A, luminal B or HER2 by all methods. To determine the agreement of these three centroid classifications, we used the freemarginal Kappa statistics of Brennan and Prediger [29] and saw substantial agreement in the classification of 


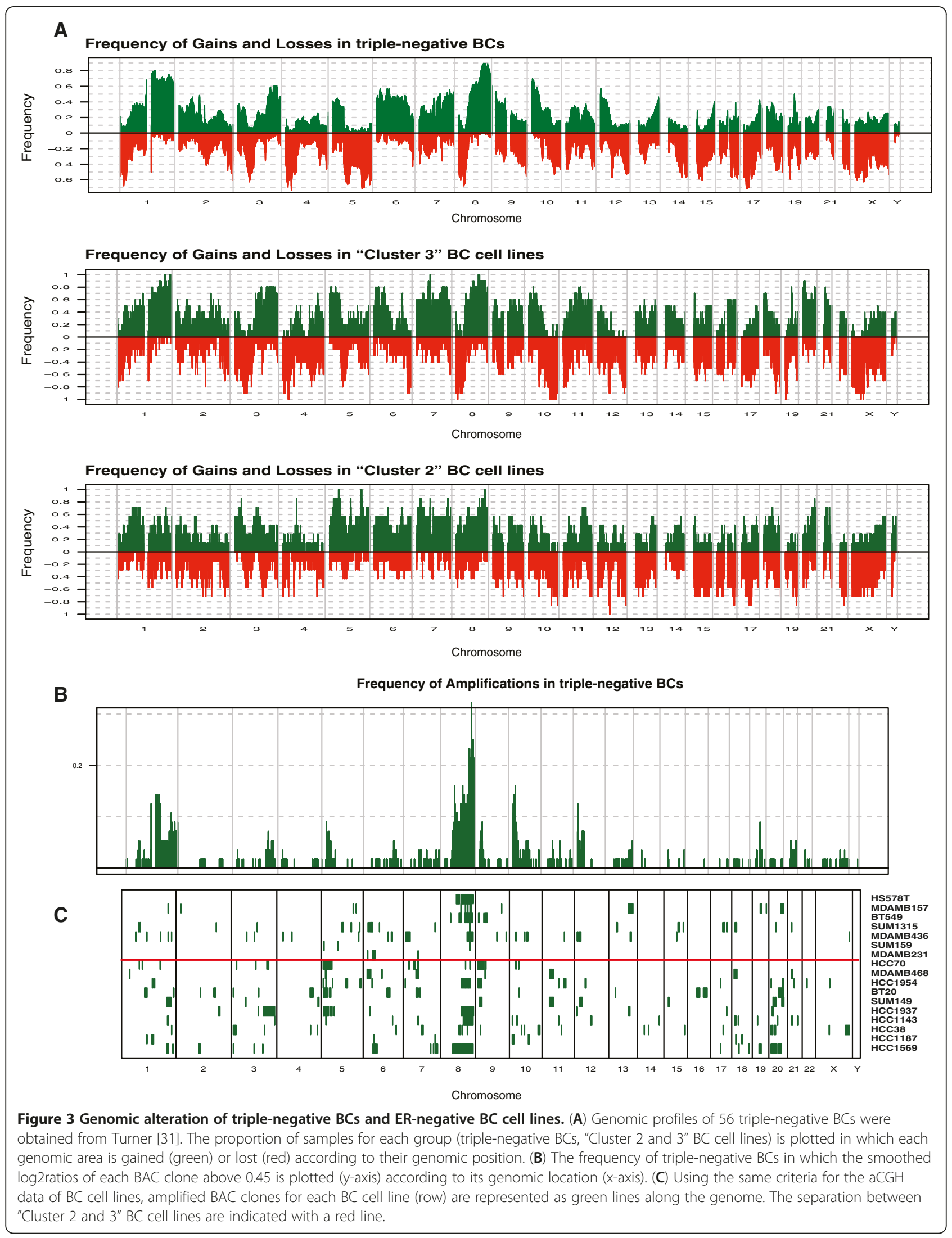


the basal-like (Kappa score $=0.78$ ), luminal A (Kappa score $=0.7)$ and HER2 subtypes (Kappa $=0.63)$, in agreement with the results of previous studies $[7,30]$.

\section{Copy number aberrations and associated gene expression changes in BC cell lines represent those observed in triple-negative $\mathrm{BCs}$}

To identify $\mathrm{BC}$ cell lines harbouring copy number aberrations specific for triple-negative $\mathrm{BC}$, we performed aCGH using a 32k tiling path array platform and surveyed their genomic changes (individual aCGH-profiles are provided as Additional file 3 Figure S1). By grouping the $\mathrm{BC}$ cell lines based on the three expression clusters, "Cluster 2" cell lines displayed significantly less highlevel amplifications and deletions compared with the other two clusters (Additional file 4 Figure S2). Next, we retrieved CNAs identified in our previous study on 56 triple-negative BCs [31], analysed on the same genomic platform. Overall the frequency of gains and losses seen in triple-negative BCs was more similar to "Cluster 3" than to "Cluster 2" and "Cluster 1" cell lines (Figure 3A). Recurrent amplification seen in primary triple-negative $\mathrm{BCs}$ were recapitulated in at least one $\mathrm{BC}$ cell line (Additional file 5 Table S3). The most highly recurrent triple-negative $\mathrm{BC}$-specific amplicons in $\mathrm{BC}$ cell lines were on 5p15.33-p15.1 (HCC1143, HCC1937, HCC1954, HCC70, MDAMB468 and BT20), followed by 9p24.3-22.3 and $7 q 11.1$ found in 6 "Cluster 3" cell lines and 4 "Cluster 3 " cell lines, respectively (Figure 3B). Given that these regions are also characterised by common polymorphisms, genes such as JAK2 (9p24) [32], NUNS2 (5p15) [33] or LIMK1 (7q11) [34] previously associated with breast cancers, and gained preferentially in basal-like breast cancers [35] might validate that these regions contain genes providing a selective advantage for triple-negative BCs. A comprehensive integration of genes lost or gained in the 2,000 breast cancer study is provided in Additional file 6 Table S4. Amplifications on 3q24q25.1, 3q25.32-q25.33, 5p14.3-p14.1, 7p11.2 and 9p22.3 were observed only in "Cluster 3 " cell lines, and the 13q32.3-q33.3 amplicon only in "Cluster 2" cell lines, illustrating a good representation of triple-negative $\mathrm{BC}$ specific CNAs in ER-negative cell lines, with some of them having a higher prevalence in one than the other expression defined group. We and others have previously demonstrated that the expression levels of certain genes located in triple-negative BCs specific CNAs is copy number dependent $[31,36]$. To investigate if these dependencies are also recapitulated in $\mathrm{BC}$ cell lines, we integrated expression data with cbs-smoothed aCGH profiles of each BC cell lines. Using Pearson's correlation (fdr adjusted $P_{-}$value <0.05), 4,571 genes showed significantly correlation between their expression and DNA copy number levels (Additional file 6 Table S4).
This set encompassed 1,158/2,064 triple-negative BC copy-number dependent genes as determined by Turner [31], and included genes such as transcriptional regulators $(n=98)$, kinases $(n=47)$, phosphatases $(n=24)$ and transmembrane receptors $(\mathrm{n}=5)$, as well as biomarkers for diagnosis $(n=42)$, prognosis $(n=14)$, disease progression $(\mathrm{n}=7)$ and known drug targets $(\mathrm{n}=20)$ (Additional file 5 Table S4). Triple-negative $\mathrm{BC}$-specific amplicons, recurrently amplified in our BC cell lines (e.g. 5p15.33-p15.1 and 9p24.3-22.3) and harbouring genes with DNA copy number-dependent expression levels are shown in Figure 4. Among those were genes, such as JAK2, NSUN2 and NFIB previously shown to have pathogenic roles, but also novel potential drivers e.g. PPAPDC or RANBP6, which could be selectively required for the survival of cells harbouring those amplification (Figure 4).

\section{Epigenetic influence on sub-type specific genes in ER-negative BC cell lines}

The functional validity of the methylation pattern found on CpG islands in cultured cancer cell lines has been the matter of controversy [37]. To study epigenetic patterns in $\mathrm{BC}$ cell lines, we produced genome-wide methylation profiles on Illumina GoldenGate bead arrays. Unsupervised hierarchical clustering using 1,223 CpG probes, corresponding to 707 genes, revealed a different grouping (Additional file 7 Figure S3) as it was observed when their expression profiles were clustered (Figure 1). To validate that the $\mathrm{BC}$ cell line specific methylation pattern can be also found in triple-negative $\mathrm{BC}$, we retrieved methylation data of 189 fresh-frozen BCs performed on the same microarray [38]. Due to the lack of HER2 status information in their study, 43 basal-like BCs were used as surrogates for triple-negative tumours and $165 \mathrm{CpG}$ islands with variable methylation levels were observed. Of those 165, $128 \mathrm{CpG}$ probes showed also changes in their methylation status in our BC cell lines (Additional file 6 Table S4). Investigating the methylation state of these $\mathrm{CPG}$ islands in each $\mathrm{BC}$ cell line individually, demonstrated an overall good representation of $\geq 70 \%$ of hypo- and hyper- basal-like BCspecific methylation events specifically in ER-negative BC cell lines (Additional file 8 Figure S4). Given that BC subtype specific expression has been suggested to be under epigenetic influence [38], we surveyed the methylation effect on gene expression in BC cell lines. Integration of methylation and gene expression data resulted in 1,129 CpG gene pairs (corresponding to 652 genes) and identified an inverse correlation between methylation and gene expression levels for 93 pairs (correlation < 0.55; adjusted $P_{-}$value 0.05 ). Performing bootstrap analysis by randomly sampling the $\mathrm{BC}$ cell lines, we showed that the number of significant association between gene 


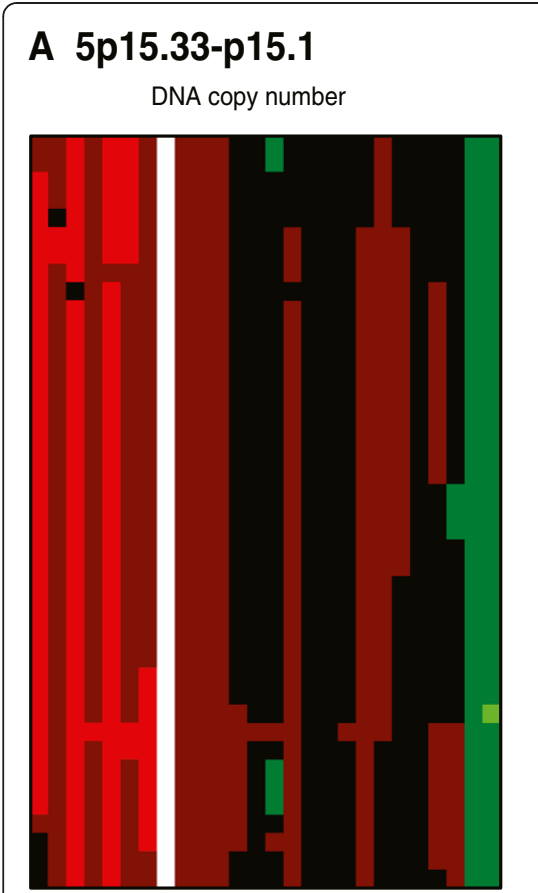

Amplified

Not_Amplified

\section{B 9p24.3-p22.3}

DNA copy number

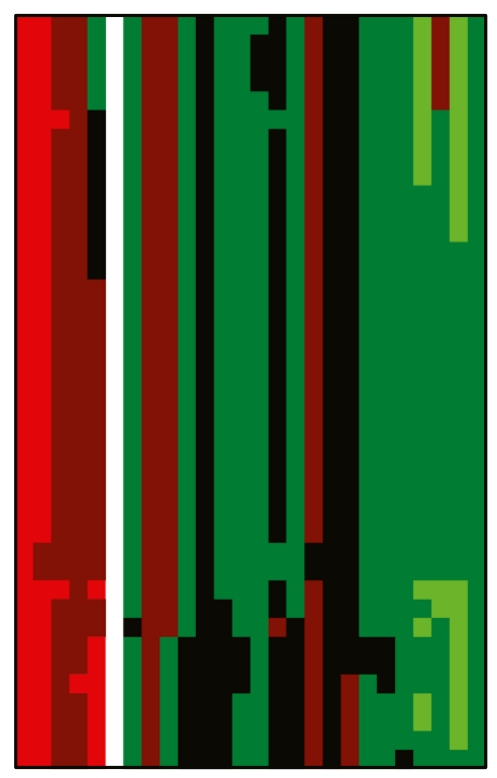

Amplified

Not_Amplified

\section{DNA copy number}

gene amplification

_ gene gain

no copy number change

heterozygous copy number loss

homozygous copy number loss
Expression

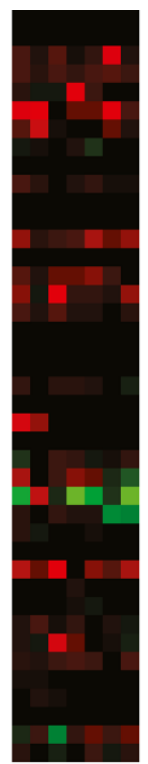

Amplified

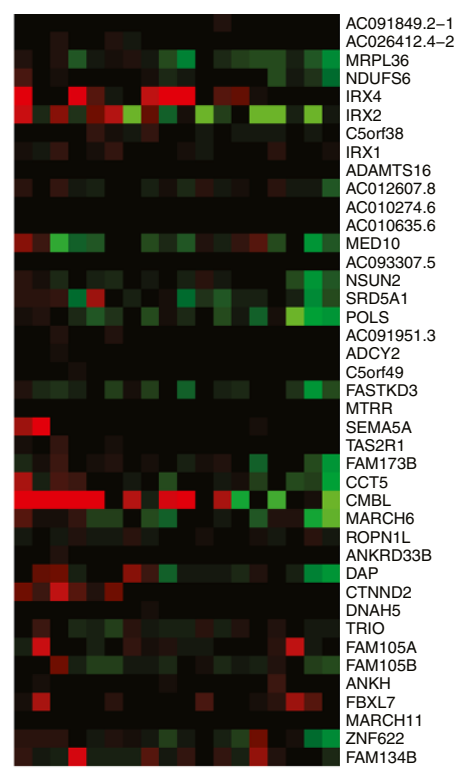

Not_Amplified

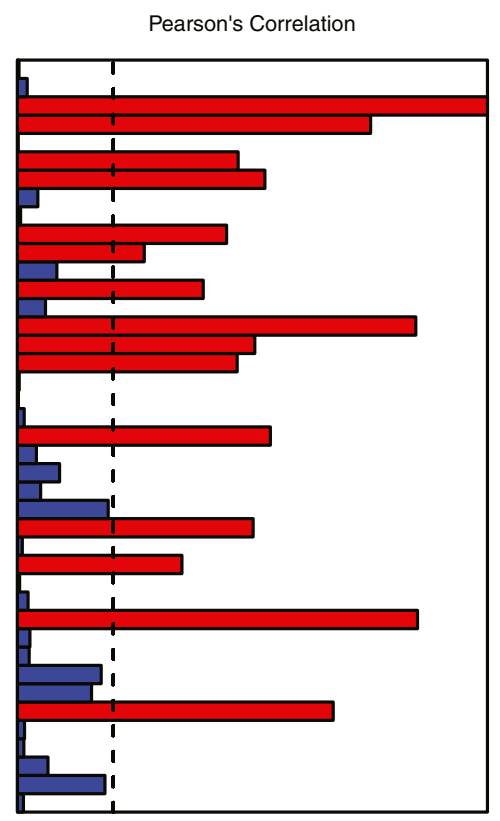

p.value threshold -0.05
Expression

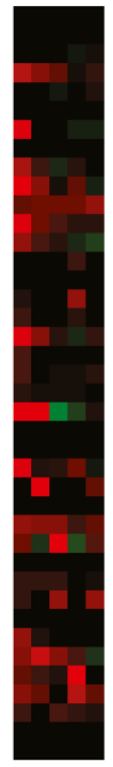

Amplified

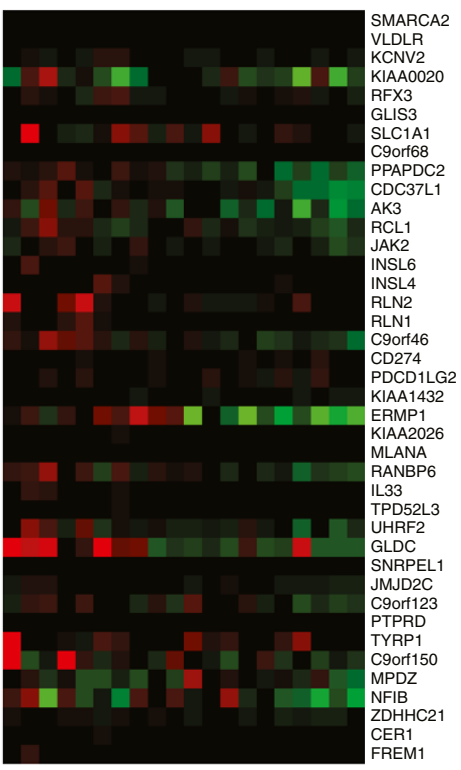

Not_Amplified
Pearson's Correlation

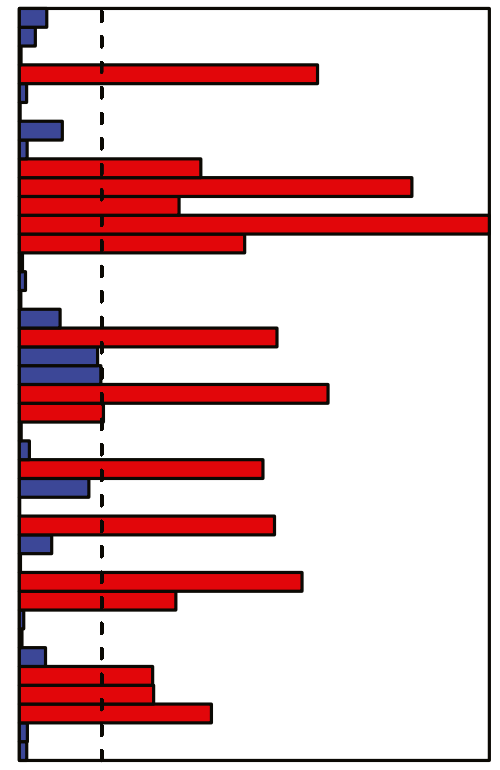

p.value threshold -0.05

gene expression

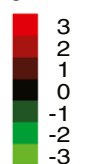

Figure 4 (See legend on next page.) 
(See figure on previous page.)

Figure 4 BC cell lines recapitulate recurrent triple-negative BC-specific amplicons and their possible drivers. Matched heatmaps of gene expression and $\mathrm{aCGH}$ within regions of recurrent amplification in BC cell lines (A) and (B). Cell lines were split into those with amplification (AMP) and those without (NA). Heatmap of aCGH (left) shows amplification in red, deletion in green and no change in black for each corresponding chromosomal location of the respective gene. Expression heatmap (middle) indicates if expression values for the gene are above (red) or below (green) the median value. Barplots (right) illustrate of a Pearson's correlation analysis between expression and DNA copy number levels. Black dotted lines show adjusted $P_{-}$value threshold of 0.05 .

expression and methylation was more than 90 fold higher than expected. Using these $93 \mathrm{CpG}$ gene pairs in a multiclass SAM analysis revealed 73 with specific methylation patterns over the three expression clusters, particularly distinguishing "Cluster 2" cell lines from the others (Figure 5). As described previously, "Cluster 2" cell lines exhibited among others, expression patterns similar to the "Claudin.low" gene signature [8]. Fifteen

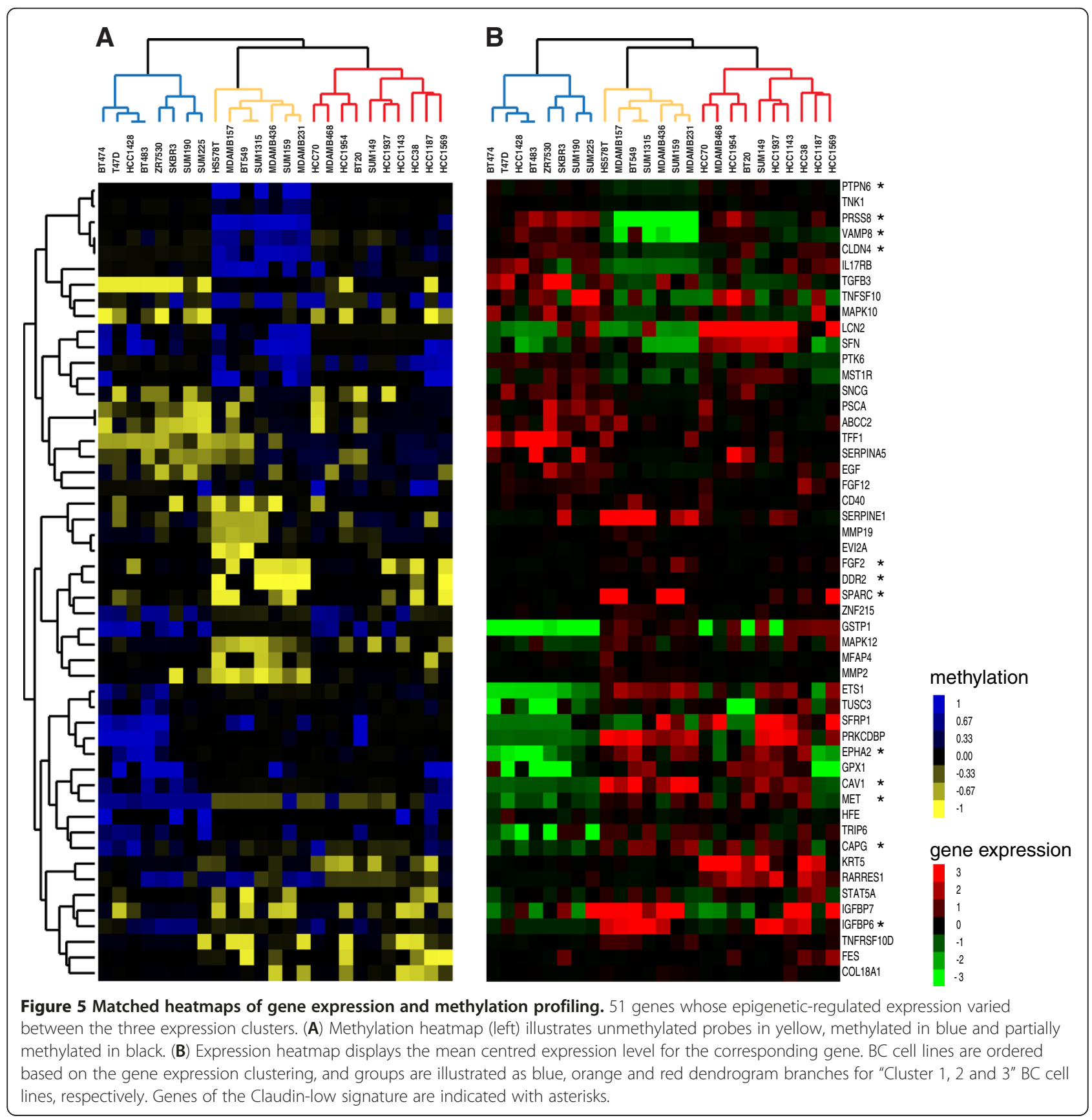


genes of the "Claudin.low" gene signature had CpG sites with varying methylation pattern over these $\mathrm{BC}$ cell lines which was significantly higher than expected by chance (hypergeometric testing $P_{-}$values $<0.001$ ), whereby genes downregulated in "Claudin.low" cancers according to "Claudin.low" signature were methylated and vice-versa, such as "Claudin.low" signature genes such as PRSS8, CLDN4 and VAMP8 were downregulated in "Cluster 2" and their $\mathrm{CpG}$ islands were methylated, while genes like SPARC or DDR2 had unmethylated CpG islands and showed higher abundance in these $\mathrm{BC}$ cell lines. By comparing those with epigenetic-regulated genes in breast cancers [38], we identified 12 genes with the same concordant pattern (asterisks, Figure 5). Taken together, our analyses demonstrate that BC cell lines retain methylation-dependent gene expression patterns observed in basal-like BCs, and strengthen an epigenetic influence on some $\mathrm{BC}$ phenotypes that are retained in their equivalent model systems.

\section{Discussion}

Triple-negative BCs represent a heterogeneous group with diverse deregulation of biological pathways. Here, we extended the molecular characterisation of ER-negative $\mathrm{BC}$ cell lines based on their genetic, epigenetic and transcriptional profiles, and correlated these with a comprehensive compendium of gene signatures reflecting different features of ER-negative BCs [8,9,28,39-45]. Initial cluster analysis of $\mathrm{BC}$ cell lines' expression profiles resulted in three groups, two clusters encompassing purely ER-negative $\mathrm{BC}$ cell lines ("Cluster 3" and "Cluster 2"), while one consisted of three ER-negative and all ER-positive $\mathrm{BC}$ cell lines. The first two cell line clusters were in good agreement with recent $\mathrm{BC}$ cell line studies $[6,11,15-18,31,46]$. While "Cluster 2" encompassed cell lines that were all represented in the Basal "B" cluster of Neve et al. [18] and were assigned to the triple-negative mesenchymal phenotype by Lehmann et al. [11], most of the "Cluster 3" cell lines were part of Neve's Basal "A" cluster [18] and part of the basal-like subtype according to Lehmann et al., [11]. Our "Cluster 3" cell lines exhibited expression patterns found in transcriptional profiles of microdissected grade 3 triple-negative breast tumours [43] as well as grade 3 versus grade 1 breast carcinomas [9,47]. HCC1143, an ER-negative/HER2-negative cell line, was the top in vitro representative "Cluster 3" cell line for the triple-negative phenotype of microdissected grade 3 triple-negative breast tumours [43]. The transcriptional profile of HCC1143 also seemed very suitable in modelling the Interferon, IGF1 and MET signalling pathways. BC cell lines with expression patterns most closely associated with the Apocrine.Basal subtype [9] were not defined to one or the other cluster and HCC1954, an ER-negative/HER2-positive cell line of "Cluster 3" displayed the highest representation. These BCs were originally defined on the basis of their androgen receptor level and many of them harboured ERBB2 amplifications [9]. This is in agreement with our findings, whereby using a recently published $\mathrm{BC}$ classifier, named CIT, three ER-negative/HER2-positive cell lines SKBR3, SUM190 and SUM225 were classified to the mApo (molecular Apocrine) breast cancer subtype [10]. In a study, MDAMB453, SUM185, CAL148 and MFM223 showed expression patterns associated with androgen receptor signalling and were more sensitive to androgen receptor antagonist bicalutamide and an Hsp90 inhibitor [11]. While none of those cell lines were part of our study, BT549 and HCC1937, BC cell lines used in our study and good representatives of the Apocrine. Basal subtype showed high sensitivity to Hsp90 inhibitors in Lehmann's work [11]. The Claudin-low subtype has been described as $\mathrm{BC}$ entity $[8,48]$, which is enriched for ER-negative invasive ductal carcinomas, while displaying low levels of luminal differentiation markers and activation of pathways involved in epithelial-to-mesenchymal transition, stem cell-like features and the immune response [8]. Integration of gene expression with methylation data over $\mathrm{BC}$ cell lines revealed a group of $\mathrm{CpG}$ islands corresponding to genes within the Claudin-low signature, showing an inverse correlation between their methylation and the genes expression in $\mathrm{BC}$ cell lines and BCs [38]. Our findings are in agreement with those from a recent report that led to the identification of a set of genes whose expression was epigenetically regulated and when used as a gene signature identified mesenchymal features in Claudin-Low breast tumours [19]. Furthermore, they postulated that a deviant methylation might reflect cell lineage commitment in agreement with our hypothesis of a contribution of an epigenetic regulation to the ClaudinLow subtype. Aberrant DNA methylation events have initially been thought to accumulate in a random fashion within cells in pre-malignant tissues, however, lately it has also been shown that de novo methylation has a predictable pattern, creating plasticity followed by commitment to alternative cell lineages [49]. Holm and colleagues proposed that $\mathrm{BC}$ subtypes might be driven by different epigenetic events and could reflect their different cellular origins [38]. Nevertheless, an alternative hypothesis might also be that the methylation patterns are a result from mutations in genes controlling the epigenetic landscape in breast cancer [50]; thus further investigation is warranted to determine whether these distinctive methylation patterns are results of genetic aberration in epigenetic regulator genes and/or contribute to delineation of the differentiation hierarchy of Claudin-Low and other BC subtypes.

We and others have recently shown that basal-like $\mathrm{BCs}$ are most likely derived from luminal progenitor 
cells [51,52]. Identifying in vitro models would enhance our understanding of these cell populations. Interestingly, our cluster and gene signature analysis revealed ERresponsive features for SKBR3, SUM190 and SUM225, three ER-negative/HER2-positive cell lines. SKBR3 cells are well known to have luminal BC characteristics [53]. In contrast, the classification of SUM190 and SUM225 is controversial. While some $\mathrm{BC}$ cell line studies assigned them to basal-like cell lines [15,18], others supported our finding of SUM190 within the ER-positive cluster [16]. SUM225, although not included in this study, was classified as of luminal phenotype in other studies [54]. Common to both is the expression of luminal cytokeratins 8,18 and 19 [55] as well as genes found in luminal progenitor cell population (data not shown) [51], more consistent with a luminal classification. Although SUM225 was found to highly express ALDH1, a marker for the so-called BC stem cells [56], further investigations are necessary to ascertain whether SUM190 and SUM225 represent appropriate in vitro models for luminal intermediate progenitor populations.

High-level amplifications are less likely to represent random aberrations and often encompass genes driving the development or maintenance of tumour growth. Three-quarters of triple-negative BCs harbour at least one amplicon [31], however, their recurrence rates are lower than those of high-level CNAs found in ER-positive/ HER2-negative and HER2-positive BC subtypes (e.g. ERBB2amplicon in HER2, and CCND1 and FGFR1 in luminal breast tumours [57]). Here, we demonstrated that triplenegative $\mathrm{BC}$-specific amplicons are recapitulated in ER-negative BC cell lines and that some of them are associated with higher frequencies either to "Cluster 2" or "Cluster 3" expression clusters. For example, the region on 5 p15.33-p15.1 was found to be recurrently amplified in 5/56 and 10/28 triple-negative BCs [31,36], was present in six "Cluster 3" but only in one "Cluster 2" cell lines. Notably, these genomic sites map to regions of common germline copy number polymorphism and the functional consequences of their increased DNA levels require further validation. Nevertheless, several genes located within these amplified regions were found gained with a higher frequency in basal-like BCs in a recent study investigating 2,000 breast tumours [35] and expression levels significantly correlated with their DNA copy number in triple-negative $\mathrm{BC}$ cell lines and tumours for several of these genes [31]. A recent study investigated genes on 5p15.33-p15.1 in more detail and showed that silencing of the overexpressed and amplified NUNS2, a MYC target gene, reduced cell number in some BC cell lines [33]. NUNS2 expression has been found significantly increased in malignant tissues whereas it could only be found in testis in normal tissues, furthermore its role in stabilising the mitotic spindle and phosphorylation by Aurora-B make it an interesting target for cancer diagnostics and molecular therapeutics.

\section{Conclusion}

Taken together, transcriptional, genomic and epigenetic profiles of $25 \mathrm{BC}$ cell lines, enriched for those representing triple-negative features, help to define cell lines that most closely capture individual examples of the heterogeneous characteristics within triple-negative BCs. By cross-referencing different high-resolution datasets, we provide useful resources to further study transcriptional, as well as genetic and epigenetic modulation and inform the best selection of available in vitro models for the identification and validation of potential novel therapeutic targets relevant to triple-negative $\mathrm{BCs}$.

\section{Methods}

\section{BC cell lines}

BT20, BT474, BT483, BT549, Hs578T, MDAMB157, MDAMB231, MDAMB436, MDAMB468, T47D, SKBR3, ZR75-30, HCC1937, HCC70, HCC1428, HCC1143, HCC38, HCC1187, HCC1569, HCC1954 were obtained from ATCC (Manassas, VA, USA). SUM159, SUM149, SUM1315, SUM225, SUM190 were purchased from Asterand plc (Detroit, MI, USA) (Additional file 1 Table S1). All lines were grown according to the supplier's recommendation and authenticated by means of Short Tandem Repeat (STR) analysis (PowerPlex ${ }^{\circledR} 1.2$ System, Promega, WI, US) as previously described [58]. STR profiles were matched to the German Collection of Microorganisms and Cell Cultures (DSMZ)-database (www.dsmz.com). BC cell lines were stratified into mesenchymal and epithelial-like morphological groups based on previous studies $[11,16,18]$.

\section{RNA and DNA isolation}

Cells were grown to $\sim 70 \%$ confluence before harvesting nucleic acids. DNA was prepared using the Qiagen DNeasy tissue kit (Qiagen, Valencia, CA) and RNA was isolated using Trizol (Invitrogen, Carlsbad, CA) according to the manufacturers' protocol. DNA concentration was measured with Picogreen (Invitrogen, Paisley, UK). Integrity of RNA was quantified using the Agilent 2100 Bioanalyser with RNA Nano LabChip Kits (Agilent Biosystems, Foster City, CA).

\section{Microarray analyses}

Analyses of microarray data were performed in the $\mathrm{R}$ environment 2.12.0 (http://www.r-project.org/) making use of several Bioconductor packages (www.bioconductor. org/). All Microarray probes and external gene signatures were mapped to the Ensembl 55 (human genome build 37) to ensure uniform annotation. Microarray data have been deposited in Array Express (E-TABM-928; http:// 
www.ebi.ac.uk/arrayexpress/). A Sweave document describing the statistical analysis is provided as Supplemental Methods (Addition file 9).

\section{Gene expression profiling}

Using the Illumina Totalprep RNA amplification kit (Ambion, UK), 200ng total BC cell line RNA was amplified and hybridised to Illumina HumanWG-6v2.0 arrays gene expression bead-chips at Genizon BioSiences Inc (Quebec, CA). Raw data obtained from Illumina BeadStudio (Illumina, San Diego, CA) were preprocessed using the "lumi" -Bioconductor package [59]. Microarray probes absent in more than $80 \%$ of samples based on an Illumina BeadStudio detection $P_{-}$value $>0.01$ were removed from further analysis. For unsupervised hierarchical clustering of gene expression, 5,693 unique Ensembl genes with a median absolute deviation (MAD) of $\geq 0.4$ across all BC cell lines were selected. Ward clustering was applied to genes and arrays after median centring using Pearson's correlation as a distance measurement and 10,000 bootstrap iterations were performed to assess the significance of the observed the stability of the clusters using the pvclust package for $\mathrm{R}$ [60]. Resulting clusters were visualised with Java TreeView [61]. Two strategies were applied for gene expression signature analysis: (1) When centroids for specific classes (e.g. BC subtypes or groups of ER-negative breast tumours [25]) were publicly available, assignment of $\mathrm{BC}$ cell lines to these classes was based on their highest Spearman rank correlation. Classification included class centroids defined by Sorlie [27], $\mathrm{Hu}$ [28], Parker [26], Prat [8], CIT256 [10] and Teschendorff [25]. (2) To monitor specific ER-related features, 11 gene signatures were retrieved from publication (see Additional file 3 Table S2 for a detailed description). For the "G3.TN.Tumour" signature, we used our previously published expression data of microdissected breast tumours [43]. Significance Analysis of Microarrays (SAM) [62] with 1,000 permutations and $0 \% \mathrm{fdr}$ was used to identify significant genes for triple-negative BCs, using a twoclass comparisons between tumours belonging to the triple-negative subtype and all other subtypes. For each $\mathrm{BC}$ cell line, a weighted mean expression of genes present in the respective signature was determined, and cell lines were ranked based on their concordance.

\section{Array-based comparative genomic hybridisation (aCGH)}

Labelling, hybridisation, image and initial data analysis of the $32 \mathrm{k}$ BAC tiling path aCGH platform, produced at the Breakthrough Breast Cancer Research Centre, London, UK [63] was carried out as previously described [43]. Breakpoint analysis was performed using the circular binary segmentation (cbs) algorithm [64] and rescaled such that the genome MAD was the same in each sample.
Only segments of $\geq 3$ BAC clones were used in further analyses. Thresholds for cbs-smoothed data were estimated as described previously [65]. Briefly, cbs-smoothed

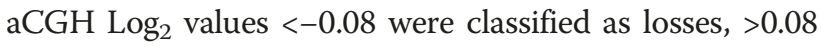
but $\leq 0.45$ were categorised as gains, and $>0.45$ were referred to as high-level gains/ amplifications. To determine genomic instability, the fraction of amplified, deleted or total BACs over the whole data set was calculated and presented as a proportion. Gene expression values were compared with median cbs-smoothed aCGH data for all BACs encompassing the genomic position using Pearson's correlation adjusted for multiple testing [66]. Matched heatmaps between gene expression and genomic data were created as described in [31] showing the minus $\log _{10}$ Pearson's P_value of each gene-aCGH pair correlation. The raw and cbs-smoothed aCGH data are deposited at http://rock.icr.ac.uk/collaborations/GrigoriadisA/.

\section{Methylation array analysis}

Hybridisation and image analysis of the Illumina GoldenGate methylation beadarrays were performed at the Genome Centre (Barts and the London School of Medicine and Dentistry, London, UK). Methylation profiles of the BC cell lines, obtained through the BeadStudio Methylation Module (Illumina, San Diego, CA), was normalised by dichotomising the un- /methylated CpG islands separately before equalising their median according to the "methylumi" package (www.bioconductor.org/). CpG sites located on the $\mathrm{X}$ chromosomes were removed, as well as constitutively un-/ methylated probes, resulting in 1,223 CpG sites (data are available at http://rock.icr.ac. $\mathrm{uk} /$ collaborations/GrigoriadisA/). The methylation state of CpG islands given as a ß-value [67] was stratified into three categories: $\beta$-values $\leq 0.25, \geq 0.75$ and between $\geq 0.25$ and $\leq 0.75$; and interpreted as un- /, methylated and partially methylated $\mathrm{CpG}$ sites, respectively. These cut-offs are slightly more stringent than Holm et al. has used them for the analysis of breast carcinomas using the same methylation array platform [38] to increase the chances of true-positive events. Initial analysis revealed a similar methylation frequency in all BC cell lines, determined as the fraction of methylated $\mathrm{CpG}$ sites, affecting on average $31 \%$ of all CpG islands. Using a total of 10,000 permutations to obtain reasonable estimates of dependencies, sample labels were permuted and correlation analyses between gene expression and methylation values were carried out on the resampled data set.

\section{Additional files}

Additional file 1: Table S1. Clinicopathological features of breast cell lines. Clinicopathological characteristics of BC cell lines. 
Additional file 2: Table S2. Gene signatures with relevance in ERnegative breast tumours. Compendium of gene signatures, listing their genes, their citation and their relevance for triple-negative BCs.

Additional file 3: Figure S1. aCGH profiles Of BCCLs.zip. Folder provided aCGH-profiles for each BCCL individually. Gains are coloured in green, while copy number loss is shown in red.

Additional file 4: Figure S2. Distribution of CNAs over 3 gene expression clusters. Genomic instability varies between different BC cell lines expression clusters. For each BC cell line the genomic instability was determined, defined as the fraction of altered genome, and compared between the three expression clusters. Total genomic aberrations, amplifications and deletions were investigated separately. P_values (Welch t-test) for pairwise comparison are shown in red.

Additional file 5: Table S3. Recurrent amplicons of 56 Grade 3 TNBC in BCCLs. Recurrent amplicons of TNBC found in BC cell lines of "Cluster 1,2 and $3^{\prime \prime}$.

Additional file 6: Table S4. Gene centric analysis in 25 BCCL. Gene centric table of BC cell lines, showing the copy number state of each gene in each BC cell line, their un/adjusted Pearson's correlation between gene expression and copy number; their correlation between gene expression and copy number in triple-negative BCs (both taken from Turner [31] their methylation states in BC cell lines, their Pearson's correlation between methylated state and their gene expression in $\mathrm{BC}$ cell lines and basal-like BCs [38].

Additional file 7: Figure S3. Hierarchical clustering of BCCL methylation data. Unsupervised hierarchical clustering of BC cell lines based CpG islands. BC cell lines of "Cluster 1, 2, 3" are shown in blue, orange and red, respectively.

Additional file 8: Figure S4. Distribution of methylated and unmethylated $\mathrm{CpG}$ islands in each $\mathrm{BCCL}$. representation of $\mathrm{BC}$ specific un/methylated CpG sites in BC cell lines. Methylation marks for triplenegative $B C$ were retrieved from Holm's methylation profiling analysis [38]. Barplots represent the number of un/methylated CpG islands in each BC cell lines as identified of being un/methylated in BCs. BC cell lines of "Cluster 1, 2, 3" are shown in blue, orange and red, respectively. The order of the BC cell lines is based on their gene expression clustering.

Additional file 9: Sweave Documentation. Sweave documentation of analysis.

\section{Abbreviations}

BC: Breast cancer; ER: Estrogen-receptor; PR: Progesterone receptor; CNAs: Copy Number Aberrations; MAD: Median Absolute Deviation; SAM: Significance Analysis of Microarrays; ACGH: Array-based comparative genomic hybridisation; CBS: Circular binary segmentation; BAC: Bacterial Artificial Chromosome; AMP: Amplification.

\section{Competing interests}

The authors have declared no conflict of interests.

\section{Authors' contributions}

Conceived and designed the experiments: AG, AM, EN, RN, JSR-F and AT. Performed the experiments: PJW, RN and JF. Analysed the data: AG, AM. Wrote the paper: AG, EN, JSR-F and AT. All authors read and approved the final manuscript.

\section{Acknowledgments}

This study was funded by Breakthrough Breast Cancer. This research was supported by the Experimental Cancer Medicine Centre at King's College London and also by the National Institute for Health Research (NIHR) Biomedical Research Centre based at Guy's and St Thomas' NHS Foundation Trust and King's College. RN, JT and JSR-F acknowledge NHS funding for the NIHR Biomedical Research Centre. The views expressed are those of the author(s) and not necessarily those of the NHS, the NIHR or the Department of Health. We would like to thank Dr. Alice Gao and Prof. Marketa Zevlebil for providing access to the ROCK database. We are also grateful to Dr Olorunsola Agbaje for advise in statistical analysis.

\section{Author details}

'Breakthrough Breast Cancer Research Unit, Guy's Hospital, King's Health Partners AHSC, King's College London School of Medicine, London SE1 9RT, UK. ${ }^{2}$ The Breakthrough Breast Cancer Research Centre, The Institute of Cancer Research, London, UK. ${ }^{3}$ Current affiliation: Department of Pathology and Human Oncology and Pathogenesis Program, Memorial Sloan-Kettering Cancer Center, New York, NY 10065, USA.

Received: 18 June 2012 Accepted: 31 October 2012

Published: 14 November 2012

\section{References}

1. Rakha EA, Ellis 1O: Triple-negative/basal-like breast cancer: review. Pathology 2009, 41(1):40-47.

2. Reis-Filho JS, Tutt AN: Triple negative tumours: a critical review. Histopathology 2008, 52(1):108-118.

3. Voduc D, Nielsen TO: Basal and triple-negative breast cancers: impact on clinical decision-making and novel therapeutic options. Clin Breast Cancer 2008, 8(Suppl 4):S171-178.

4. Foulkes WD, Smith IE, Reis-Filho JS: Triple-negative breast cancer. N Engl Med 2010, 363(20):1938-1948.

5. Cheang MC, Voduc D, Bajdik C, Leung S, McKinney S, Chia SK, Perou CM, Nielsen TO: Basal-like breast cancer defined by five biomarkers has superior prognostic value than triple-negative phenotype. Clin Cancer Res 2008, 14(5):1368-1376.

6. Geyer FC, Weigelt B, Natrajan $R$, Lambros MB, de Biase D, Vatcheva $R$, Savage K, Mackay A, Ashworth A, Reis-Filho JS: Molecular analysis reveals a genetic basis for the phenotypic diversity of metaplastic breast carcinomas. J Pathol 2010, 220(5):562-573.

7. Weigelt B, Mackay A, A'Hern R, Natrajan R, Tan DS, Dowsett M, Ashworth A, Reis-Filho JS: Breast cancer molecular profiling with single sample predictors: a retrospective analysis. Lancet Oncol 2010, 11(4):339-349.

8. Prat A, Parker JS, Karginova O, Fan C, Livasy C, Herschkowitz J, He X, Perou $\mathrm{CM}$ : Phenotypic and molecular characterization of the claudin-low intrinsic subtype of breast cancer. Breast Cancer Res 2010, 12(5):R68.

9. Farmer $\mathrm{P}$, Bonnefoi $H$, Becette $V$, Tubiana-Hulin M, Fumoleau P, Larsimont D, Macgrogan G, Bergh J, Cameron D, Goldstein D, et al: Identification of molecular apocrine breast tumours by microarray analysis. Oncogene 2005, 24(29):4660-4671.

10. Guedj M, Marisa L, de Reynies A, Orsetti B, Schiappa R, Bibeau F, MacGrogan $G$, Lerebours $F$, Finetti $P$, Longy $M$, et al: A refined molecular taxonomy of breast cancer. Oncogene 2012, 31(9):1196-1206.

11. Lehmann BD, Bauer JA, Chen $X$, Sanders ME, Chakravarthy AB, Shyr $Y$, Pietenpol JA: Identification of human triple-negative breast cancer subtypes and preclinical models for selection of targeted therapies. J Clin Invest 2011, 121(7):2750-2767.

12. Sotiriou C, Pusztai L: Gene-expression signatures in breast cancer. N Engl J Med 2009, 360(8):790-800.

13. Lacroix M, Leclercq G: Relevance of breast cancer cell lines as models for breast tumours: an update. Breast Cancer Res Treat 2004, 83(3):249-289.

14. Barretina J, Caponigro G, Stransky N, Venkatesan K, Margolin AA, Kim S, Wilson CJ, Lehar J, Kryukov GV, Sonkin D, et al: The Cancer Cell Line Encyclopedia enables predictive modelling of anticancer drug sensitivity. Nature 2012, 483(7391):603-607.

15. Chin K, DeVries S, Fridlyand J, Spellman PT, Roydasgupta R, Kuo WL, Lapuk A, Neve RM, Qian Z, Ryder T, et al: Genomic and transcriptional aberrations linked to breast cancer pathophysiologies. Cancer Cell 2006, 10(6):529-541.

16. Kao J, Salari K, Bocanegra M, Choi YL, Girard L, Gandhi J, Kwei KA, Hernandez-Boussard T, Wang P, Gazdar AF, et al: Molecular profiling of breast cancer cell lines defines relevant tumor models and provides a resource for cancer gene discovery. PLoS One 2009, 4(7):e6146.

17. Mackay A, Tamber N, Fenwick K, Iravani M, Grigoriadis A, Dexter T, Lord CJ Reis-Filho JS, Ashworth A: A high-resolution integrated analysis of genetic and expression profiles of breast cancer cell lines. Breast Cancer Res Treat 2009, 118(3):481-498.

18. Neve RM, Chin K, Fridlyand J, Yeh J, Baehner FL, Fevr T, Clark L, Bayani N, Coppe JP, Tong F, et al: A collection of breast cancer cell lines for the study of functionally distinct cancer subtypes. Cancer Cell 2006, 10(6):515-527. 
19. Sproul D, Nestor C, Culley J, Dickson JH, Dixon JM, Harrison DJ, Meehan RR Sims AH, Ramsahoye BH: Transcriptionally repressed genes become aberrantly methylated and distinguish tumors of different lineages in breast cancer. Proc Natl Acad Sci USA 2011, 108(11):4364-4369.

20. Perou CM, Sorlie T, Eisen MB, van de Rijn M, Jeffrey SS, Rees CA, Pollack JR, Ross DT, Johnsen H, Akslen LA, et al: Molecular portraits of human breast tumours. Nature 2000, 406(6797):747-752.

21. Savage $K$, Lambros MB, Robertson $D$, Jones $R L$, Jones $C$, Mackay $A$, James $M$, Hornick JL, Pereira EM, Milanezi F, et al: Caveolin 1 is overexpressed and amplified in a subset of basal-like and metaplastic breast carcinomas: a morphologic, ultrastructural, immunohistochemical, and in situ hybridization analysis. Clin Cancer Res 2007, 13(1):90-101.

22. Linderholm BK, Hellborg H, Johansson U, Elmberger G, Skoog L, Lehtio J, Lewensohn R: Significantly higher levels of vascular endothelial growth factor (VEGF) and shorter survival times for patients with primary operable triple-negative breast cancer. Ann Oncol 2009, 20(10):1639-1646.

23. Klingbeil $P$, Natrajan R, Everitt G, Vatcheva R, Marchio C, Palacios J, Buerger $H$, Reis-Filho JS, Isacke CM: CD44 is overexpressed in basal-like breast cancers but is not a driver of $11 \mathrm{p} 13$ amplification. Breast Cancer Res Treat 2010, 120(1):95-109.

24. Savage K, Leung S, Todd SK, Brown LA, Jones RL, Robertson D, James M, Parry S, Rodrigues Pinilla SM, Huntsman D, et al: Distribution and significance of caveolin 2 expression in normal breast and invasive breast cancer: an immunofluorescence and immunohistochemical analysis. Breast Cancer Res Treat 2008, 110(2):245-256.

25. Teschendorff AE, Miremadi A, Pinder SE, Ellis IO, Caldas C: An immune response gene expression module identifies a good prognosis subtype in estrogen receptor negative breast cancer. Genome Biol 2007, 8(8):R157.

26. Parker JS, Mullins M, Cheang MC, Leung S, Voduc D, Vickery T, Davies S, Fauron C, He X, Hu Z, et al: Supervised risk predictor of breast cancer based on intrinsic subtypes. J Clin Oncol 2009, 27(8):1160-1167.

27. Sorlie T, Tibshirani R, Parker J, Hastie T, Marron JS, Nobel A, Deng S, Johnsen $H$, Pesich R, Geisler S, et al: Repeated observation of breast tumor subtypes in independent gene expression data sets. Proc Natl Acad SC USA 2003, 100(14):8418-8423.

28. Hu Z, Fan C, Oh DS, Marron JS, He X, Qaqish BF, Livasy C, Carey LA, Reynolds $E$, Dressler $L$, et al: The molecular portraits of breast tumors are conserved across microarray platforms. BMC Genomics 2006, 7:96.

29. Brennan RL, Prediger DJ: Coeffecient kappa: some uses, misuses, and alternatives. Educ Psychol Meas 1981, 41:687-699.

30. Haibe-Kains B, Desmedt C, Loi S, Culhane AC, Bontempi G, Quackenbush J, Sotiriou C: A three-gene model to robustly identify breast cancer molecular subtypes. J Natl Cancer Inst 2012, 104(4):311-325.

31. Turner N, Lambros MB, Horlings HM, Pearson A, Sharpe R, Natrajan R, Geyer FC, van Kouwenhove M, Kreike B, Mackay A, et al: Integrative molecular profiling of triple negative breast cancers identifies amplicon drivers and potential therapeutic targets. Oncogene 2010, 29(14):2013-2023.

32. Ding L, Ellis MJ, Li S, Larson DE, Chen K, Wallis JW, Harris CC, McLellan MD, Fulton RS, Fulton LL, et al: Genome remodelling in a basal-like breast cancer metastasis and xenograft. Nature 2010, 464(7291):999-1005.

33. Frye M, Dragoni I, Chin SF, Spiteri I, Kurowski A, Provenzano E, Green A, Ellis IO, Grimmer D, Teschendorff A, et al: Genomic gain of $5 \mathrm{p} 15$ leads to overexpression of Misu (NSUN2) in breast cancer. Cancer Lett 2010, 289(1):71-80.

34. Wang W, Mouneimne G, Sidani M, Wyckoff J, Chen X, Makris A, Goswami S, Bresnick AR, Condeelis JS: The activity status of cofilin is directly related to invasion, intravasation, and metastasis of mammary tumors. J Cell Biol 2006, 173(3):395-404.

35. Curtis C, Shah SP, Chin SF, Turashvili G, Rueda OM, Dunning MJ, Speed D, Lynch AG, Samarajiwa S, Yuan Y, et al: The genomic and transcriptomic architecture of 2,000 breast tumours reveals novel subgroups. Nature 2012, 486(7403):346-352

36. Han W, Jung EM, Cho J, Lee JW, Hwang KT, Yang SJ, Kang JJ, Bae JY, Jeon YK, Park IA, et al: DNA copy number alterations and expression of relevant genes in triple-negative breast cancer. Gene Chromosome Canc 2008, 47(6):490-499.

37. Hinshelwood RA, Clark SJ: Breast cancer epigenetics: normal human mammary epithelial cells as a model system. J Mol Med 2008, 86(12):1315-1328.

38. Holm K, Hegardt C, Staaf J, Vallon-Christersson J, Jonsson G, Olsson H, Borg A, Ringner M: Molecular subtypes of breast cancer are associated with characteristic DNA methylation patterns. Breast Cancer Res 2010, 12(3):R36.
39. Creighton CJ, Casa A, Lazard Z, Huang S, Tsimelzon A, Hilsenbeck SG, Osborne CK, Lee AV: Insulin-like growth factor-I activates gene transcription programs strongly associated with poor breast cancer prognosis. J Clin Oncol 2008, 26(25):4078-4085.

40. Creighton CJ, Li X, Landis M, Dixon JM, Neumeister VM, Sjolund A, Rimm DL, Wong H, Rodriguez A, Herschkowitz Jl, et al: Residual breast cancers after conventional therapy display mesenchymal as well as tumorinitiating features. Proc Natl Acad Sci USA 2009, 106(33):13820-13825.

41. Hoadley KA, Weigman VJ, Fan C, Sawyer LR, He X, Troester MA, Sartor Cl, Rieger-House T, Bernard PS, Carey LA, et al: EGFR associated expression profiles vary with breast tumor subtype. BMC Genomics 2007, 8:258.

42. Kaposi-Novak P, Lee JS, Gomez-Quiroz L, Coulouarn C, Factor VM, Thorgeirsson SS: Met-regulated expression signature defines a subset of human hepatocellular carcinomas with poor prognosis and aggressive phenotype. J Clin Invest 2006, 116(6):1582-1595.

43. Natrajan R, Lambros MB, Rodriguez-Pinilla SM, Moreno-Bueno G, Tan DS, Marchio C, Vatcheva R, Rayter S, Mahler-Araujo B, Fulford LG, et al: Tiling path genomic profiling of grade 3 invasive ductal breast cancers. Clin Cancer Res 2009, 15(8):2711-2722.

44. Shipitsin M, Campbell LL, Argani P, Weremowicz S, Bloushtain-Qimron N, Yao J, Nikolskaya T, Serebryiskaya T, Beroukhim R, Hu M, et al: Molecular definition of breast tumor heterogeneity. Cancer Cell 2007, 11(3):259-273.

45. West RB, Nuyten DS, Subramanian S, Nielsen TO, Corless CL, Rubin BP, Montgomery K, Zhu S, Patel R, Hernandez-Boussard T, et al: Determination of stromal signatures in breast carcinoma. PLOS Biol 2005, 3(6):e187.

46. Natrajan R, Weigelt B, Mackay A, Geyer FC, Grigoriadis A, Tan DS, Jones C, Lord CJ, Vatcheva R, Rodriguez-Pinilla SM, et al: An integrative genomic and transcriptomic analysis reveals molecular pathways and networks regulated by copy number aberrations in basal-like, HER2 and luminal cancers. Breast Cancer Res Treat 2010, 121(3):575-589.

47. Cordenonsi M, Zanconato F, Azzolin L, Forcato M, Rosato A, Frasson C, Inui M, Montagner M, Parenti AR, Poletti A, et al: The Hippo transducer TAZ confers cancer stem cell-related traits on breast cancer cells. Cell 2011, 147(4):759-772.

48. Herschkowitz JI, Simin K, Weigman VJ, Mikaelian I, Usary J, Hu Z, Rasmussen KE, Jones LP, Assefnia S, Chandrasekharan S, et al: Identification of conserved gene expression features between murine mammary carcinoma models and human breast tumors. Genome Biol 2007, 8(5):R76

49. Reynolds PA, Sigaroudinia M, Zardo G, Wilson MB, Benton GM, Miller CJ, Hong C, Fridlyand J, Costello JF, TIsty TD: Tumor suppressor p16INK4A regulates polycomb-mediated DNA hypermethylation in human mammary epithelial cells. J Biol Chem 2006, 281(34):24790-24802

50. Garber K: Genetic discoveries propagate new epigenetic drugs. J Natl Cancer Inst 2012, 104(3):174-176.

51. Lim E, Vaillant F, Wu D, Forrest NC, Pal B, Hart AH, Asselin-Labat ML, Gyorki $D E$, Ward T, Partanen A, et al: Aberrant luminal progenitors as the candidate target population for basal tumor development in BRCA1 mutation carriers. Nat Med 2009, 15(8):907-913.

52. Molyneux G, Geyer FC, Magnay FA, McCarthy A, Kendrick H, Natrajan R, Mackay A, Grigoriadis A, Tutt A, Ashworth A, et al: BRCA1 basal-like breast cancers originate from luminal epithelial progenitors and not from basal stem cells. Cell Stem Cell 2010, 7(3):403-417.

53. Charafe-Jauffret E, Ginestier C, Monville F, Finetti P, Adelaide J, Cervera N, Fekairi S, Xerri L, Jacquemier J, Birnbaum D, et al: Gene expression profiling of breast cell lines identifies potential new basal markers. Oncogene 2006, 25(15):2273-2284.

54. Behbod F, Kittrell FS, LaMarca H, Edwards D, Kerbawy S, Heestand JC, Young E, Mukhopadhyay P, Yeh HW, Allred DC, et al: An intraductal human-inmouse transplantation model mimics the subtypes of ductal carcinoma in situ. Breast Cancer Res 2009, 11(5):R66.

55. Forozan F, Veldman R, Ammerman CA, Parsa NZ, Kallioniemi A, Kallioniemi OP, Ethier SP: Molecular cytogenetic analysis of 11 new breast cancer cell lines. Br J Cancer 1999, 81(8):1328-1334.

56. Charafe-Jauffret E, Ginestier C, Birnbaum D: Breast cancer stem cells: tools and models to rely on. BMC Cancer 2009, 9:202.

57. Reis-Filho JS, Savage K, Lambros MB, James M, Steele D, Jones RL, Dowsett M: Cyclin D1 protein overexpression and CCND1 amplification in breast carcinomas: an immunohistochemical and chromogenic in situ hybridisation analysis. Mod Pathol 2006, 19(7):999-1009. 
58. Brough R, Frankum JR, Sims D, Mackay A, Mendes-Pereira AM, Bajrami I, Costa-Cabral S, Rafiq R, Ahmad AS, Cerone MA, et al: Functional viability profiles of breast cancer. Cancer Discov 2011, 1(3):260-273.

59. Du P, Kibbe WA, Lin SM: lumi: a pipeline for processing Illumina microarray. Bioinformatics 2008, 24(13):1547-1548.

60. Suzuki R, Shimodaira H: Pvclust: an R package for assessing the uncertainty in hierarchical clustering. Bioinformatics 2006, 22(12): 1540-1542.

61. Saldanha AJ: Java Treeview-extensible visualization of microarray data. Bioinformatics 2004, 20(17):3246-3248.

62. Tusher VG, Tibshirani R, Chu G: Significance analysis of microarrays applied to the ionizing radiation response. Proc Natl Acad Sci USA 2001, 98(9):5116-5121.

63. Lacroix-Triki M, Suarez PH, MacKay A, Lambros MB, Natrajan R, Savage K, Geyer FC, Weigelt B, Ashworth A, Reis-Filho JS: Mucinous carcinoma of the breast is genomically distinct from invasive ductal carcinomas of no special type. J Pathol 2010, 222(3):282-298.

64. Lai WR, Johnson MD, Kucherlapati R, Park PJ: Comparative analysis of algorithms for identifying amplifications and deletions in array CGH data. Bioinformatics 2005, 21(19):3763-3770.

65. Duprez R, Wilkerson PM, Lacroix-Triki M, Lambros MB, Mackay A, Hern RA, Gauthier A, Pawar V, Colombo PE, Daley F, et al: Immunophenotypic and genomic characterization of papillary carcinomas of the breast. J Pathol 2012, 226(3):427-441.

66. Benjamini $Y$, Hochberg $Y$ : Controlling the false discovery rate: a pratical and powerful approach to multiple testing. J Royal Stat Soc B 1995, 57:289-300

67. Bibikova M, Lin Z, Zhou L, Chudin E, Garcia EW, Wu B, Doucet D, Thomas NJ, Wang Y, Vollmer E, et al: High-throughput DNA methylation profiling using universal bead arrays. Genome Res 2006, 16(3):383-393.

68. Sotiriou C, Wirapati P, Loi S, Harris A, Fox S, Smeds J, Nordgren H, Farmer P, Praz $V$, Haibe-Kains B, et al: Gene expression profiling in breast cancer: understanding the molecular basis of histologic grade to improve prognosis. J Natl Cancer Inst 2006, 98(4):262-272.

69. Hu X, Stern HM, Ge L, O'Brien C, Haydu L, Honchell CD, Haverty PM, Peters BA, Wu TD, Amler LC, et al: Genetic alterations and oncogenic pathways associated with breast cancer subtypes. Mol Cancer Res 2009. 7(4):511-522.

doi:10.1186/1471-2164-13-619

Cite this article as: Grigoriadis et al:: Molecular characterisation of cell line models for triple-negative breast cancers. BMC Genomics 2012 13:619.

\section{Submit your next manuscript to BioMed Central and take full advantage of:}

- Convenient online submission

- Thorough peer review

- No space constraints or color figure charges

- Immediate publication on acceptance

- Inclusion in PubMed, CAS, Scopus and Google Scholar

- Research which is freely available for redistribution 